\title{
Designing Road Safety Interventions for Young Drivers: the Power of Peer Influence
}

Weston, L

http://hdl.handle.net/10026.1/11087

Transportation Research Part F: Traffic Psychology and Behaviour

Elsevier

All content in PEARL is protected by copyright law. Author manuscripts are made available in accordance with publisher policies. Please cite only the published version using the details provided on the item record or document. In the absence of an open licence (e.g. Creative Commons), permissions for further reuse of content should be sought from the publisher or author. 
Designing Road Safety Interventions for Young Drivers - The Power of Peer Influence

Lauren Weston \& Elizabeth Hellier

School of Psychology, University of Plymouth, Plymouth, Devon, UK 


\section{Abstract}

Peer passengers are associated with risky driving behaviour and increased collision rate in young drivers, but the mechanism by which young drivers are influenced by their peers is not well understood. Here we report two studies that explore the effect of peer influence on young drivers. The first explored the relationship between susceptibility to peer influence and young drivers' engagement in risky driving behaviour. 163 young drivers completed self-report measures of risky driving behaviour and susceptibility to different forms of peer influence. Results showed that young drivers who were influenced by their peers to attain social prestige and through peers intervening in their decisions committed more driving violations. The second study sought to utilise the susceptibility of young drivers to peer influence by using peers to design and deliver a safety intervention, following the ' $U$ in the Driver Seat' model from the US. When compared to a traditional fear appeal and a control, the peer intervention group reported safer attitudes and intentions to drive safely at follow-up. Together these studies provide insight into how peers influence young drivers' risky behaviour, and support the notion of using peer education tools in young driver safety interventions.

\section{Keywords}

Young drivers; road safety intervention; peer passengers; peer influence; peer to peer 


\section{Introduction}

Young novice drivers (under 25 years) are involved in more collisions than older drivers (ONS, 2014). These collisions are more likely to be classed the fault of the young driver and more often result in death or serious injury (DfT; 2015; Clarke et al., 2010). Road deaths account for $25 \%$ of deaths amongst 15-19 year olds, compared to $0.5 \%$ of deaths in the wider population and so understanding the factors that underpin young drivers' increased collision risk is imperative so that we can target them effectively with safety interventions.

The presence of peer passengers is one of the key factors implicated in the risky driving behaviour and increased collision rate of young drivers (e.g. Rice, Peek-Asa \& Kraus, 2003). Young drivers use driving as a means of socialising with their peers and are likely to have passengers more often, and to have a greater number of passengers per trip, than older drivers (Shope \& Bingham, 2008). Unfortunately, it seems that young drivers are also more likely to engage in high risk behaviours such as speeding (Moller \& Haustein, 2014; Rhodes, Pivik \& Sutton, 2015), drink driving (Bingham et al., 2007; Fernandes et al., 2010), not wearing a seatbelt (Williams \& Shabanova, 2002) and night time/weekend driving (Doherty, Andrey \& MacGregor, 1998) when accompanied by peer passengers. Rice et al. (2003) analysed police reports of collisions involving 16-17-year-old drivers and found that driving with passengers was one of the most common predictors of a collision resulting in the driver being seriously or fatally injured.

Not only are collision rates higher for teenage drivers accompanied by teenage passengers, but these collisions are also more likely to be judged the fault of the young driver (Williams, 2003). For example, Preusser et al. (1998) analysed five years' data from the Fatality Analysis Reporting System (FARS) and found that the presence of passengers was implicated in proportionately more at-fault fatal collisions for drivers under the age of 24; whereas for older drivers the presence of passengers was neutral or a protective factor against at-fault collisions. The greatest risk for young drivers' involvement in an at-fault collision was the presence of a similar aged passenger. More recently, Williams and Tefft (2014) analysed police crash report data for the years 2005 - 2010. They found that more than $40 \%$ of 16 and 17 -year-old drivers involved in fatal crashes had teenage 
passengers; and when teen drivers were accompanied by teen passengers they were more likely to be at fault.

Ouimet et al. (2010) investigated the age of the passenger further, using data from FARS and the US National Household Travel Survey. Their results indicated that whilst young drivers were most at risk when accompanied by teenage passengers (particularly male passengers); their collision risk was reduced in the presence of adult passengers. Simons-Morton et al. (2011) collected data on young drivers' during their first 18 months of licensure. They found that collision/ near collision rates for young novices were $75 \%$ lower in the presence of adult passengers but $96 \%$ higher among teenagers with risky friends. They suggested that low rates of risky driving when accompanied by adult passengers were indicative of teenagers' ability to drive safely; but that social influence may result in riskier driving in the presence of risky friends. Ouimet et al. (2013) conducted a systematic review of the literature on peer passengers and their effect on young drivers' collision risk. They echoed the findings of Williams, Ferguson and McCartt (2007), finding a clear, consistent increased risk for peer passenger presence, particularly in fatal collisions, even when the young driver was accompanied by only one peer passenger.

It is male peer passengers that have the greatest negative effect on young drivers' risky driving. Simons-Morton et al. (2005) observed young drivers' driving behaviour when exiting high school car parks with passengers or when alone. They found that teenage drivers drove faster than the general traffic and allowed shorter headways, particularly when accompanied by a male teenage passenger. Interestingly, whilst both male and female drivers allowed shorter headways in the presence of a male teenage passenger, when male drivers were accompanied by a female passenger, they allowed greater headways. The riskiest drivers were male teens accompanied by male teenage passengers - for whom the observed rate of high risk driving was double that of general traffic. Similarly, Chen et al. (2000) analysed collision report data and found that male and female young drivers were most at risk of a fatal collision when accompanied by male passengers.

The presence of peer passengers is widely accepted as a risk factor for collisions in young drivers but the reasons why they pose such a risk remain relatively unclear. One suggestion is that adolescents are more susceptible to peer 
influence than other age groups (Steinberg, 2004), and young drivers are influenced by their peers to drive in a certain way. High susceptibility to peer influence has been linked to various measures of risky driving in young people. For example, Simons-Morton et al. (2011) found that speeding was associated with young drivers' susceptibility to peer influence, number of risky friends, tolerance of deviance, substance use and high sensation seeking. There is also some evidence supporting a neural basis for susceptibility to peer influence and risk taking in adolescence. Falk et al. (2014) found that young drivers' neural responses to social exclusion predicted an increase in simulated risk taking behaviour in the presence of a peer.

Peers can influence young drivers' behaviour either directly, through verbal encouragement, or indirectly, through the drivers' perceptions of how others think they should drive (Horvath et al., 2012). Passengers that verbally encourage the driver to perform risky behaviours are exerting 'active' influence, which is observable, involves action by the passenger and occurs within the driving context. Indirect or 'passive' influence is unobservable, originates outside the driving context and relates to the driver's perceptions of pressure from the passenger. Social Identity Theory (SIT) suggests that to strengthen feelings of group membership, people are motivated to behave in accordance with the group's norms (Tajfel, 1982). Thus young drivers are affected by passive peer influence because the presence of passengers implicitly encourages the driver to behave in accordance perceived group norms (Allen \& Brown, 2008).

The idea that young people engage in risky driving in the presence of peer passengers to fulfil perceived peer group norms, and thus are susceptible to passive peer influence, has received research support. Authors such as ScottParker, Watson and King (2009); Simons-Morton et al. (2011); Moller and Haustein (2014); Scott-Parker et al. (2014) and Taubman-Ben-Ari et al. (2015) all find that the perceptions a driver has of their friends' driving behaviour predicts their own driving behaviour. Conner et al. (2003) found that male and female drivers reported feeling normative pressure to speed, and increased speeding intentions, when with peer passengers. Similarly, Bingham et al. (2016) found that young male drivers were only more likely to display greater simulated risky driving behaviour 
when accompanied by a risk-accepting peer passenger; but not when with a riskaverse one.

Studies comparing the relative impact of active and passive peer influence have been inconclusive. Sela-Shayovitz (2008) found that only passive peer influence (apprehension about friend's evaluations and attaining social prestige) was correlated with driving violations and collision involvement. No correlations with active peer influence were found. Similarly, Ouimet et al.'s (2013) simulator study found that the mere presence of a male teenage passenger in the vehicle with a male teenage driver reduced their attention to the road. Horvath et al. (2012) later failed to replicate this finding - reporting similar levels of speeding intentions arising from both active and passive peer influence. Most recently, Gheorghiu, Delhomme and Felonneau (2015), using a scenario task, found that only active (not passive) pressure had an effect on estimated speeding behaviour.

The presence of peer passengers is widely accepted as a risk factor for collisions in young drivers, but the research into how passive and active peer influence affects young drivers is still in its infancy, and contradictory findings are emerging. The studies reported here aimed to develop our understanding of how peers influence young drivers' risky driving and to so inform the design of road safety interventions (RSIs). If young drivers engage in more violations because they perceive risky driving to be a means of gaining prestige within their peer group, we might be able to use this susceptibility to peer influence in the design of RSls - by using the peer group to exert positive influence. In the first study we explored the relationship between susceptibility to peer influence and young drivers' engagement in risky driving - specifically how different types of active and passive peer influence predicted self-reported engagement in risky driving. In the second, we used this insight to facilitate and evaluate a novel peer-to-peer education intervention. 


\section{Study 1: The relationship between different forms of peer influence and}

young drivers' self-reported engagement in risky driving

\subsection{Method}

\subsubsection{Participants}

163 drivers (137 female) aged 18 - 25 years old $(M=19.74$ years) completed the study for payment or course credit. They had held their driving licence of an average of 2 years, 2 months.

\subsubsection{Materials}

We used three self-report measures.

Susceptibility to Peer Influence (SPI): Active and passive peer influence were measured with items from Sela-Shayovitz' (2008) self-report questionnaire for young drivers. There were four subscales, each containing five items. The two passive peer influence subscales were, attaining social prestige (ASP) e.g. 'driving allows me to impress others'; and apprehension about friends' evaluations (AFE) e.g. 'what my friends think about my driving is important to me'. The two active peer influence subscales were, peer intervention in decisions (PID) e.g. 'When I'm driving my friends sometimes encourage me to speed to have fun'; and pressure to make traffic violations (PTV) e.g. 'my friends pressure me to drive after I've had an alcoholic drink'.

Resistance to Peer Influence (RPI): Steinberg \& Monahan's (2007) RPI scale consists of 10 pairs of opposing statements about inter-individual interactions, e.g. "some people go along with their friends just to keep their friends happy, BUT, other people refuse to go along with what their friends want to do, even though they know it will make their friends unhappy".

Behaviour of Young Novice Drivers Scale (BYNDS): Scott-Parker et al's (2012) BYNDS measures the risky driving behaviour of young drivers and comprises five subscales: transient violations, fixed violations, misjudgement, risky driving exposure and driving in response to mood.

\subsubsection{Procedure}

Participants completed the three self-report measures and provided demographic information on-line. 


\subsection{Results}

\subsubsection{Reliability of Measures}

Reliability analyses were conducted, the alpha scores indicate good or very good reliability for all measures: SPI $a=.83, \mathrm{RPI} a=.74$ and BYNDS $\alpha=.92$.

\subsubsection{Descriptive analyses and gender}

Table 1 describes participants' responses on all measures. Participants' mean sum road traffic violation score was 94 (range 56-160) out of a possible 220, where high numbers represent more risky behaviour. One-way ANOVAs were conducted to explore effects of gender. The analyses revealed no statistically significant differences between males and females on road traffic violations $(F(1,152)=.18$, $p>.05)$; overall passive peer influence $(F(1,152)=.97, p>.05)$, overall active peer influence $(F(1,152)=.1 .6, p>.05)$; RPI $(F(1,152)=2.6, p>.05)$; or on any of the susceptibility to peer influence subscales: ASP $(F(1,152)=.67, p>.05), \operatorname{AFE}(F(1$, $152)=.84, p>.05), \operatorname{PID}(F(1,152)=.15, p>.05)$ or $\operatorname{PTV}(F(1,152)=3.5, p>.05)$. The data was collapsed across gender for the remaining analysis.

Table 1. Susceptibility to passive peer influence, active peer influence, resistance to peer influence and prior road traffic violations

All Participants

Mean (SD)

\begin{tabular}{lc}
\hline Passive Peer Influence (scale sum) & $28.7(6.6)$ \\
\hline Passive a): Attaining Social Prestige (ASP) & $15.1(4.6)$ \\
\hline Passive b): Apprehension of Friend's Evaluations (AFE) & $13.6(3.0)$ \\
\hline Active Peer Influence (scale sum) & $23.6(6.1)$ \\
\hline Active a): Peer Intervention in Decisions (PID) & $12.6(3.4)$ \\
\hline Active b): Pressure to make Traffic Violations (PTV) & $13.7(3.5)$ \\
\hline Resistance to Peer Influence & $30.8(4.1)$ \\
\hline Road Traffic Violations (sum) & $94.1(18.7)$ \\
\hline
\end{tabular}

\subsubsection{Correlations}


Correlations presented in Table 2 suggest that when young drivers report feeling influenced by their peers they also report higher rates of various road traffic violations. Susceptibility to both active and passive peer influence is associated with self-reported driving violations. High resistance to peer influence was not associated with significantly fewer road traffic violations.

Table 2. Correlations among Variables. Note ${ }^{*} \mathrm{p}<0.5 .{ }^{* *} \mathrm{p}<.01$

\begin{tabular}{lllllllll}
\hline Variable & 1 & 2 & 3 & 4 & 5 & 6 & 7 & 8 \\
\hline $\begin{array}{l}\text { 1. Passive Peer } \\
\text { Influence }\end{array}$ & - & & & & & & & \\
\hline
\end{tabular}

2. Passive a: ASP $.93^{* *}-$

3. Passive b: AFE $\quad .81^{* *} \quad .53^{* *} \quad-$

Evaluations

4. Active Peer $\quad .80^{* *} \quad .78^{* *} \quad .59^{* *}-$

Influence

5. Active a: PID $\quad .64^{* *} \quad .66^{* *} \quad .41^{* *} \quad .89^{* *}-$

\begin{tabular}{llllll}
\hline 6. Active b: PTV & $.79^{* *}$ & $.73^{* *}$ & $.64^{* *}$ & $.90^{* *}$ & $.60^{* *}$
\end{tabular}

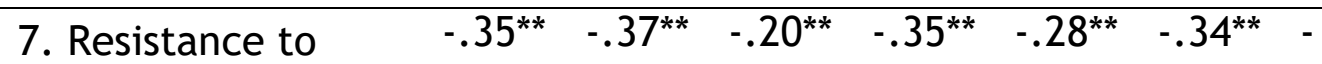

Peer Influence

$\begin{array}{llllllll}\text { 8. Road Traffic } & .53^{* *} & .56^{* *} & .32^{* *} & .57^{* *} & .59^{* *} & .43^{* *} & -.12\end{array}$

Violations

As the peer influence measures were correlated with each other, variance inflation factors (VIF) were used to assess the degree of collinearity between them. There are various recommendations in the literature regarding acceptable levels of VIF. Most commonly, a value of 10 has been regarded as the maximum level of VIF to accept (e.g. Hair et al., 1995; Kennedy, 1992; Marquardt, 1970; Neter et al., 1989); and this corresponds to the tolerance recommendation of .10. The VIFs for each of the variables in the present study (ASP, AFE, PID \& PTV) were 
$2.5,1.7,1.9$, and 2.8 respectively. These VIF levels indicate that the degree of collinearity between variables is low and they are suitable for use within a multiple regression analysis.

\subsubsection{Regression Analyses}

Hierarchical regression analysis was conducted to assess relations between the four forms of peer influence (ASP, AFE, PID \& PTV) and reported road traffic violations. The first model incorporated all four variables and found that reported road traffic violations was predicted by ASP $B=.32, t(149)=3.1, p<.01$ ) and by PID $B=.40$, $t(149)=4.6, p<.01$, but not by AFE $B=.03,(t(149)=.35, p>.05$, or PTV $B=-.15$, $t(149)=-.05 p>.05)$. ASP and PID also explained a significant proportion of the variance in reported road traffic violations (adjusted $R^{2}=.38, F(4,149)=24.5$ ). When the two non-significant measures of peer influence were removed from the model, adjusted R Square increased from .38 to .39, with an R Square change of .001 . This change was non-significant $F(2,149)=.14, p>.05$; and therefore it can be assumed that AFE and PTV do not explain any additional variance.

\subsection{Discussion}

The data suggest that high susceptibility to peer influence is related to more selfreported risky driving behaviours and that attaining social prestige (passive influence) and peers intervening in decisions (active influence) were the specific aspects of peer influence that predict violations. Resistance to peer influence was not associated with road traffic violations, and nor was apprehension of friends' evaluations or drivers feeling pressure to make traffic violations. Broadly the findings provide further evidence that when young adults report being highly susceptible to peer influence, they also report engaging in riskier driving behaviours. Following Horvath et al. (2012), both active and passive forms of peer influence are implicated in this process.

So young drivers who reported committing the most road traffic violations were most influenced by their peers in two specific ways: as a means to attain prestige within their social group and by accepting their peers' intervention in their driving. They were not influenced by 'apprehension of friends' evaluations' or 'pressure to make violations'. Together these finding suggest that young drivers 
perceive the input of their peer passengers to be collaborative, rather than coercive; and they appear to be using their passengers to help them decide their driving behaviour (be it safe or dangerous) through a shared understanding of what is appropriate driving behaviour, a group norm. In line with SIT, if risky driving is sanctioned by the peer group then the driver will engage in risky driving to attain a higher social standing.

What follows is that RSIs may be able to utilise the susceptibility of young people to peer influence - by using that influence for positive effect. There are two main ways in which our knowledge of peer influence might be used in the design of RSIs. If peers themselves challenged the perception that risky driving is an appropriate way to act, reduced the social norm, this might lessen young drivers' engagement in risky driving because the need to do it to attain prestige will have been eliminated. Second, RSIs might seek to provide young drivers with strategies to identify and resist peer influence. In the study below we design, pilot and evaluate the efficacy of a peer to peer RSI for young drivers.

\section{Study 2: Investigating the efficacy of a pilot peer-to-peer road safety intervention}

\subsection{Introduction}

The rationale for peer education is informed by SIT, social learning theory (Bandura, 1976; 1986), social inoculation (McGuire, 1964) and social norms (Baric, 1977). This background posits that friends look for advice from their friends, and are influenced by the expectations, attitudes and behaviour of the social group to which they belong (Lindsey, 1996). Peer education has been used to improve young peoples' wellbeing in many realms health behaviour, such as nutrition, sexual health and alcohol consumption, and there is evidence that it is effective (Story et al., 2002; White et al., 2009) and that peer leaders are as effective, if not more, than adult educators (Mellanby, Rees \& Tripp, 2000).

Peer education has also been used in the US to target risky driving. An early evaluation (Bell et al., 1991) found that peer tutoring improved driving and reduced errors. More recently, a peer-to-peer programme, 'Teens in the Driver 
Seat' (TITDS), launched in Texas in 2002. School-age students are provided with access to statistics, safe driving tips and "how-to" guides that promote awareness of the risks young drivers face. The students then design and deliver an intervention to their peers. An evaluation of TITDS, using multiple methods including self-report and observation, found a 200\% improvement in awareness of driving risks, $14 \%$ increase in seatbelt use, and a 30\% decrease in mobile phones while driving (Geedipally, Henk \& Fette, 2012). Two significant changes were made locally in 2002, the introduction of Graduated Driving Licensing (GDL) and the launch of TITDS. Between 2003 and 2010 Texas saw a 45\% reduction in fatal teen crashes; and year-on-year this declines further (Geedipally et al., 2012). McCart et al. (2009) suggested that GDL laws similar to those introduced in Texas should expect on average an $11 \%$ reduction in fatal crashes involving 16 -year-old drivers. So although the introduction of GDL may explain some of the reduction in fatal collisions in Texas, it is unlikely that GDL can account for all of it. In addition, regions where both GDL and TITDS have been introduced have seen a $14.6 \%$ greater reduction in teen collision fatalities than regions with only GDL. This suggests that a substantial, and significant, proportion of the reductions in teen crashes may be due to the efficacy of the programme (Geedipally et al., 2012). Encouraged by the apparent success of TITDS, the creators have devised a newer version ' $U$ in the Driver Seat', dedicated to improving the risk awareness of University-age young drivers.

To our knowledge there are currently no peer-to-peer education programmes in the UK that mirror 'Teens in the Driver Seat' or ' $U$ in the Driver Seat'. The UK-based 'Wasted Lives' is a one-day event that uses interactive peer to peer learning but the content is designed and delivered by road safety professionals. Here we adopted the TITDS model to pilot a peer education intervention for University-age students with both content and delivery controlled by the peer group. We compared this intervention with a standard 'fear appeal' road safety film - focussing on the negative and shocking consequences of collisions.

\subsection{Method}




\subsubsection{Participants}

72 drivers ( 56 female) aged 18 - 25 years ( $M=20.6$ years) participated for course credit or payment. They had held their driving licence for an average of 2 years, 9 months. Five undergraduates (aged 18 - 21 years) were recruited to become peer leaders (PLs) through the undergraduate apprenticeship scheme (an unpaid scheme offering students research experience).

\subsubsection{Design}

A longitudinal mixed design compared the effectiveness of a peer-to-peer intervention (P2P) with standard fear appeal videos (FE) and a no intervention control (CO) at two time points (within subjects) - pre-intervention and follow up. There were three dependent measures: attitudes towards risky driving, selfreported engagement in risky driving, and intentions to reduce risk.

\subsubsection{Materials}

\subsubsection{Pre-intervention and follow-up questionnaires}

The impact of the interventions was measured with two self-report measures. Risky driving behaviour (RDB), adapted from Tisdale (2013): Participants were asked how often they had committed 10 risky driving behaviours (e.g. text messaging, driving $10 \mathrm{mph}$ over speed limit) during the last month.

Attitudes and intentions towards risky driving (A\&l), adapted from Burgess (2011): A series of 18 statements probed attitudes and intentions towards risky driving (e.g. 'It's ok if you don't wear a seatbelt on short journeys').

These measures were used in preference to the BYNDS as they are quicker to complete - so reducing the risk of losing opportunity-sampled participants through an overly-long procedure.

\subsubsection{P2P Intervention Materials}

Three sets of materials, designed and produced by the PLs, defined the P2P intervention.

Young Driver Quiz: PLs conducted their own research on young driver risk factors and created an interactive road safety quiz based on the evidence they found. The quiz included 7 multiple choice answer questions and a subsequent quick-fire round for multiple winners. Example questions included: 'How much slower are 
your reaction times when driving and using a mobile phone at the same time?'; 'Taking some drugs is likely to affect your driving. What should you do?' Games with Beer Goggles: PLs led participants through 4 games (based on sobriety tests and divided attention tasks) that were designed to highlight the effects of drink-driving and distractions on driving. Participants played them while wearing special lenses, Drunkbuster Vision Impairment Goggles, also known as 'beer goggles', which replicate the visual impairment effects of excessive drinking. These goggles were provided on-loan from the Devon and Somerset Fire and Rescue Service. The games were: walking in a straight line (heel to toe with each step); picking out a driving license card from a set of irrelevant cards on the floor; throwing a tennis ball into a bucket; writing a text message whilst walking through a series of obstacles. Throughout the games a presentation was played on continuous loop, displaying facts and statistics on young drivers and drink-driving Participants also played a 'morning after calculator' game, a public drink driving tool designed by the road safety charity Brake and accessed from a web link. The calculator indicates how long it will take to be safe to drive, based on the number and type of drinks an individual has consumed. The tool used in this study is no longer available but similar resources are available elsewhere (e.g. the 'Morning After' app from Stennik, available from: http://morning-after.org.uk/).

Additional Communications: During the one-month intervention period PLs sent participants email and text reminders encouraging safe driving. Reminders focused on, speeding, drink driving, using a mobile phone and carrying peer passengers.

\subsubsection{FE Group materials}

The FE intervention was defined by three road safety awareness films that were designed by Department for Transport, Brake, and a Welsh Government Public Service Announcement (PSA). The first depicted a road traffic collision in which one of the passengers was not wearing a seat belt ( 31 secs; available at: https://www.youtube.com/watch?v=g-9JR2P4wWI). The second depicted the aftermath of a road traffic collision involving a young driver (122 secs; available at: https://www.youtube.com/watch?v=aiAn210a-J0). The third depicted a road traffic collision occurring as a result of a young driver texting while driving ( 255 secs; available at: https://www.youtube.com/watch?v=ROLCmStIw9E).

\subsubsection{Procedure}


Under the supervision of the lead researcher, PLs designed and delivered the P2P intervention. The FE group viewed the road safety videos in one sitting. All groups completed the follow-up questionnaires 4 weeks after the end of their intervention, where they were asked whether they had been exposed to any additional road safety material since the end of the intervention. The data collection schedule is described in Table 3.

Table 3. Data collection schedule

\begin{tabular}{|c|c|c|c|}
\hline Time & P2P & FE & $\mathrm{CO}$ \\
\hline Week 1 & $\begin{array}{l}\text { Pre-intervention } \\
\text { questionnaires (RDB } \\
\text { and A\&I). } \\
\text { PLs staged Young Driver } \\
\text { Quiz. }\end{array}$ & $\begin{array}{l}\text { Pre-intervention } \\
\text { questionnaires (RDB and } \\
\text { A\&l) } \\
\text { Participants viewed three } \\
\text { films embedded into the } \\
\text { study website. }\end{array}$ & $\begin{array}{l}\text { Pre-intervention } \\
\text { questionnaires (RDB and } \\
\text { A\&l ) }\end{array}$ \\
\hline Weeks 2 - 3 & $\begin{array}{l}\text { PLs sent out tips and } \\
\text { reminders via email/ } \\
\text { text message }\end{array}$ & & \\
\hline Week 4 & $\begin{array}{l}\text { PLs staged games with } \\
\text { beer goggles. }\end{array}$ & & \\
\hline Week 5 & & $\begin{array}{l}\text { Follow up questionnaires } \\
\text { (RDB and A\&l) }\end{array}$ & $\begin{array}{l}\text { Follow up } \\
\text { questionnaires (RDB and } \\
\text { A\&l) }\end{array}$ \\
\hline Week 9 & $\begin{array}{l}\text { Follow up } \\
\text { questionnaires (RDB } \\
\text { and A\&l) }\end{array}$ & & \\
\hline
\end{tabular}

\section{Results}

\subsection{Reliability of Measures}

Reliability analyses indicate reasonable internal consistency - RDB pre-intervention $a=.56$; RDB follow-up $a=.69$; A\&l pre-intervention $\alpha=.66$; A\&l follow-up $a=.68$. Although they do not achieve the optimal value $\alpha=.70$ suggested by Nunnally 
(1978), Cortina (1993) notes that the number of scale items should be considered and a reasonable alpha with few items may represent better internal consistency than a larger alpha with more items. As the measures here contained only 10 (RDB) and 18 (A\&l) items, the alpha values were considered adequate.

\subsection{Effects of the Intervention}

Where high numbers represent more risky behaviour, participants' mean sum RDB score was 15.3 (range 10-25) pre-intervention; and 14 (range 10-23) at follow-up. For A\&l scores, where high numbers represent more risky attitudes and intentions, participants' mean sum score was 36.7 (range 22-56) pre-intervention; and 35.5 (range 23-51) at follow-up. One-way ANOVAs were conducted to explore effects of gender. The analyses revealed no statistically significant differences between males and females on RDB scores pre-intervention or at follow-up $(F(1,71)=.002$, $\mathrm{p}>.05)$ and $\mathrm{F}(1,71)=.11, \mathrm{p}>.05)$; or on A\&l scores pre-intervention and follow-up $(F(1,71)=.11, p>.05$ and $F(1,71)=.27, p>.05)$. The data was collapsed across gender for the remaining analysis.

A 3 (Intervention: P2P, FE, CO) x 2 (Time: pre-intervention, follow-up) mixed model ANOVA was used to investigate the effect of intervention on RDB and A\&l scores.

For RDB there was a non-significant interaction between Intervention and Time $F(2,69)=1.2, p>0.5$. There was a significant main effect for Time $F(1,69)=17.0$, $\mathrm{p}<.001$ but not Intervention $\mathrm{F}(2,69)=.41, \mathrm{p}>.05$. Figure 1 illustrates the findings and shows that for all intervention groups (including control) RDB scores were lower (safer) at follow-up. There was no significant difference between the three groups' RDB scores pre-intervention $F(2,69)=.10$, $p>.05$ or at follow-up $F(2,69)=$ $.98, p>.05$, but a clear trend indicating that the P2P group had the safest RDB scores at follow-up. 


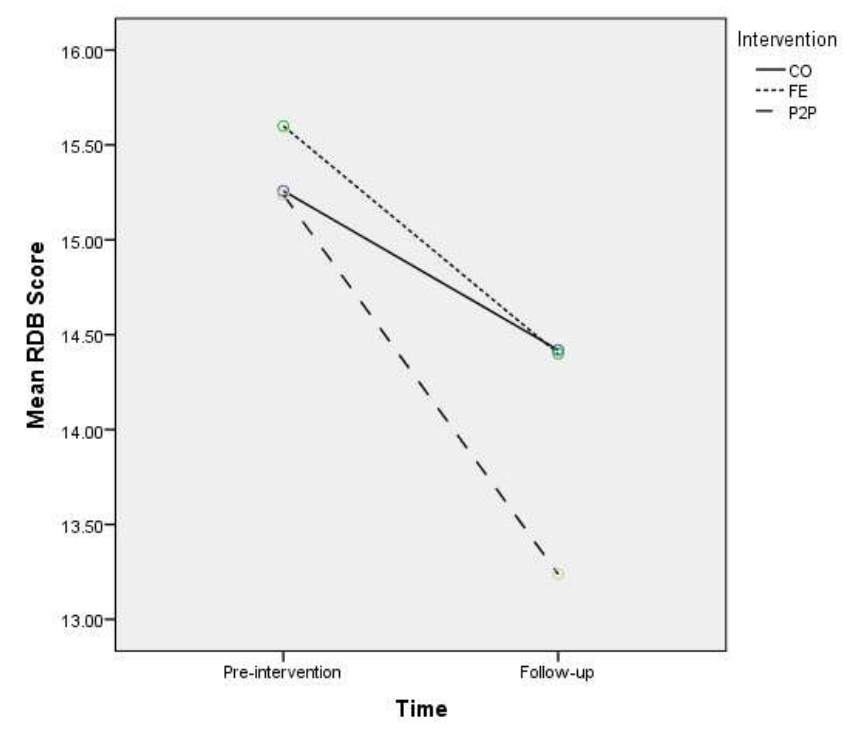

Figure 1. RDB by Intervention and Time

For A\&l there was a significant interaction between Intervention and $\operatorname{Time} F(2,69)$ $=4.5, p<.05$ and significant main effects for Intervention $F(2,69)=4.6, p<.05$ and Time $F(1,69)=5.0, p<.05$. Figure 2 illustrates that the P2P group reported safer attitudes and intentions at follow-up, whereas for the FE and $\mathrm{CO}$ groups there was no change. There was no significant difference between the three groups' A\&l scores pre-intervention $\mathrm{F}(2,69)=1.7, \mathrm{p}>.05$, only at follow-up $\mathrm{F}(2$, $69)=7.7, p<.05$. Post hoc Tukey tests showed that the P2P group's A\&t scores at follow-up differed from those of the CO group $(p<0.5)$, but not the FE group ( $p>$ $.05)$.

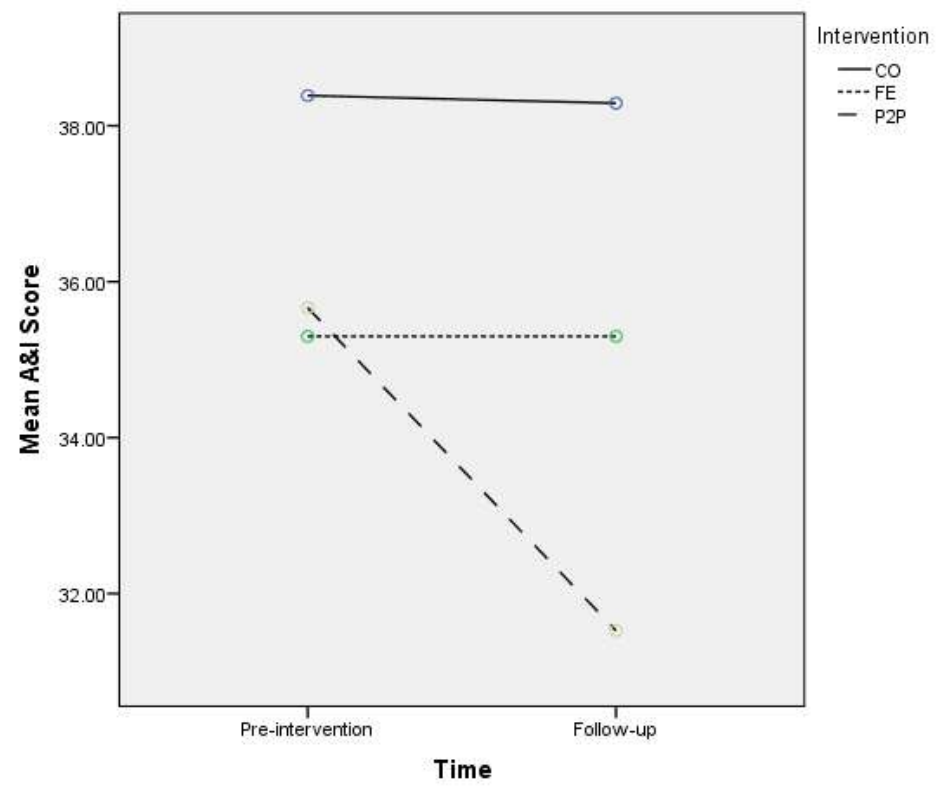

rigure L. A\&l by Intervention and I Ime 


\section{General Discussion}

The findings here are in line with previous research on peer influence in that high susceptibility to peer influence is found to be related to more self-reported risky driving behaviours. We are able to be more specific about the nature of the peer influence effect, finding that it is attaining social prestige (passive influence) and peers intervening in decisions (active influence) that predict self-reported driving violations. When susceptibility to peer influence is utilised for the good - by using peers to design and deliver a safer driving intervention, the intervention results in safer attitudes and intentions at follow-up. This work adds to the evidence in favour of peer to peer education in road safety. Geedipally, Henke \& Teffe (2012) evaluated the Teens in the Driver Seat programme, and found improved risk awareness, seat belt use, and reductions in mobile use while driving, in teenagers. Using a similar model for the peer to peer intervention, our work indicates that the value of peer to peer education may extend beyond teens, and also be effective for young people in their early twenties, who are still also influenced by their peers.

Some evaluations have failed to find consistently positive effects on risky driving of peer education. Cristini et al. (2005) evaluated the effects of a peer education intervention on young peoples' alcohol use and drink driving. Three months the intervention, peer education participants had increased knowledge of the risks of driving after drinking, but they didn't report any improvements in their attitudes toward drink driving or drink driving behaviour. Concluding that peer education had an impact on participants' knowledge, but not behaviour, the authors suggested this might have been because the intervention was a one-off event, which did not provide an adequate 'dose of intervention'. They suggested that peer education might need multiple 'doses of intervention' to produce longterm changes in behaviour. Fylan (2009) also found that the Wasted Lives programme had limited long-term success and considered that this might be a result of it being a one-off event. The peer-to-peer intervention administered here was conceived with these previous evaluations in mind and was deliberately not a one-off event, but was active for four weeks. Participants had many opportunities during the intervention to have the safe driving message reinforced, through multiple events and email reminders. 
Peer-to-peer interventions tend to differ from more traditional forms of intervention as they rely much less heavily on the use of fear appeal techniques. Previous evaluations have found that fear appeals have limited efficacy, despite their substantial cost and continued use (e.g. McKenna, 2010). In addition, it has been suggested that young driver RSIs need to incorporate a wider range of behavioural change techniques to better support them in becoming safer (Fylan \& Stradling, 2014). The intervention presented here moved away from the fear appeal model and instead used young people to challenge the perception that risky driving is a means of gaining social standing within the peer group. By doing this, the intention was that young drivers would not feel the need to engage in high-risk behaviour and thus would report lower intentions to drive dangerously. Siegel's (2014) research supports this strategy, he suggested that removing the 'rewarding' aspects of risky driving would make young drivers less likely to want to engage in it (Siegel, 2014). In this way if a young driver's social group no longer considers risky driving to be acceptable, then they will have nothing to gain by engaging in it, and this should lead to safer driving.

The use of peer education for improving young drivers' risky behaviour is in its infancy; and we note the over-representation of female participants within the studies reported here, potentially limiting the generalisability of the findings. However peer education has been used in various other adolescent risky health domains such as improved nutrition (Story et al, 2002), less alcohol consumption (White et al, 2009) and less smoking (Mellanby et al, 2000), with evidence of success for both males and females. Despite endorsements from various sources advocating the development of this form of intervention in road safety (e.g. Cristini et al., 2005) few studies document their existence or evaluate their efficacy. The findings here support the idea that peer education might be a useful way to reduce young drivers' risk and provides a starting-point to further develop peer-to-peer education.

\section{Acknowledgements}

We thank the participating students for taking part in this study; in particular the Peer Leaders who gave up their time to create and deliver a valuable road safety 
intervention. The research described in this paper was funded by the University of Plymouth.

\section{References}

Allen, J.P., \& Brown, B. B. (2008) Adolescents, peers, and motor vehicles: the perfect storm? American Journal of Preventative Medicine, 35, 289-293.

Bandura, A. (1976). Self-reinforcement: Theoretical and methodological considerations. Behaviorism, 4, 135-155.

Bandura, A. (1986). Social foundations of thought and action: A social cognitive theory. Englewood Cliffs, NJ: Prentice-Hall.

Baric, L. (1977). Social expectations vs. personal preferences-two ways of influencing health behaviour. Journal of the Institute of Health Education, 15, 23-28.

Bell, K. E., Young, K. R., Salzberg, C. L., \& West, R. P. (1991). High school driver education using peer tutors, direct instruction, and precision teaching. Journal of Applied Behavior Analysis, 24, 45-51.

Bingham, C., Raymond, E., Michael,R., Shope, J.T. (2007). Social and Behavioral Characteristics of Young Adult Drink/Drivers Adjusted for Level of Alcohol Use. Alcoholism: Clinical and Experimental Research, 31, 655-664.

Bingham, C., Simons-Morton, B.G., Pradhan, A.K., Li, K., Almani, F., Falk, E.B., Shope, J.T., Buckley, L., Ouimet, M.L., \& Albert, P.S. (2016). Peer passenger norms and pressure: Experimental effects on simulated driving among teenage males. Transportation Research Part F, 41, 124-137.

Burgess, C. (2011).An evaluation of the Learn2Live Road Safety Intervention for Young People. Retrieved 20 September 2012 from http://people.exeter.ac.uk/cnwburge/pages/2011_Executive_summary.pdf

Chen, L., Braker, S. P., Braver, E. R., \& Li, G. (2000). Carrying passengers as a risk factor for crashes fatal to 16 - 17-year-old drivers. Journal American Medical Association, 283, 15781617.

Clarke, D.D., Ward, P., Bartie, C., \& Truman, W. (2010). Killer crashes; fatal road traffic accidents in the UK. Accident Analysis and Prevention, 42, 764-770. 
Conner, M., Smith, N., \& Mcmillan, B. (2003). Examining normative pressure in the theory of planned behaviour: Impact of gender and passengers on intentions to break the speed limit. Current Psychology: Developmental, Learning, Personality, Social, 22, 252-263.

Cortina, J.M. (1993). What is coefficient alpha? An examination of theory and applications. Journal of Applied Psychology, 78, 98 - 104.

Cristini, F., Chiara Forcella, M., Santinello, M., Vieno, A., \& Zuccaro, P. (2005). Evaluation of a peer education project: Alcohol use and alcohol related driving risk during adolescence. European Journal of School Psychology, 3, 271 - 291.

Department for Transport. (2015). Road Casualties Great Britain: 2014, Retrieved 26 September, 2015 from https://www.gov.uk/government/statistics/reported-road-casualties-greatbritain-annual-report-2014

Doherty, S. T., Andrey, J. C., \& MacGregor, C. (1998). The situational risks of young drivers: The influence of passengers, time of day, and day of week on accident rates. Accident Analysis and Prevention, 30, 45 - 52.

Falk, E.B., Cascio, C.N., Carp, J., Tinney, F.J., Bingham, C.R., Shope, J.T., Ouimet, M.C., Pradhan, A.K., \& Simons-Morton, B.G. (2014). Neural Responses to Exclusion Predict Susceptibility to Social Influence. Journal of Adolescent Health, 54, 22 - 31.

Fernandes, R., Hatfield, J., \& Job, R. F.S. (2010). A systematic investigation of the differential predictors for speeding, drink-driving, driving while fatigued, and not wearing a seat belt among young drivers. Transportation Research Part F, 13, 179 - 196.

Fylan, F. (2009). What effect does Wasted Lives have on young people's road user attitudes and behaviour? Retrieved $10^{\text {th }}$ March 2014 from http://www.wastedlives.co.uk/images/research.pdf

Fylan F., \& Stradling, S. (2014). Behavioural Change Techniques used in road safety interventions for young people. European Review of Applied Psychology, special issue "Transport psychology: Identification of road users' risks and attitudes and behaviour change”, 64, 123-129.

Geedipally S.R., Henk, R.H., Fette, B. (2012). Effectiveness of Teens in the Driver Seat safety program in Texas. (submitted for publication) Journal of Transportation Statistics. 
Gheorghiu, A., Delhomme, P., \& Felonneau, M.L. (2015). Peer pressure and risk taking in young drivers' speeding behaviour. Transportation Research Part F: Traffic Psychology and Behaviour, 35, $101-111$.

Hair, J. F. Jr., Anderson, R. E., Tatham, R. L. \& Black, W. C. (1995). Multivariate Data Analysis (3 $3^{\text {rd }}$ ed). New York: Macmillan.

Horvath, C., Lewis, I., \& Watson, B. (2012) Peer passenger identity and passenger pressure on young drivers' speeding intentions. Transportation Research Part F: Traffic Psychology and Behaviour, 15, 52-64.

Kennedy, P. (1992). A Guide to Econometrics. Oxford: Blackwell.

Lindsey, B. J. (1996). Peer education: a view point and critique. Journal of the American College of Health, 45, 187-189.

Marquardt, D. W. (1970). Generalized inverses, ridge regression, biased linear estimation, and nonlinear estimation. Technometrics, 12, 591-256.

McCartt, A.T., Teoh, E.R., Fields, M., Braitman, K.A., \& Hellinga, L.A. (2009). Graduated licensing laws and fatal crashes of teenage drivers: a national study. Arlington, VA: Insurance Institute for Highway Safety.

McGuire, W.J. (1964). Inducing resistance to persuasion: Some contemporary approaches. In L. Berkowitz (Ed.), Advances in Experimental Social psychology (Vol. 1), New York: Academic. McKenna, F. (2010). Education in Road Safety-Are We Getting It Right? - Report for RAC Foundation. Retrieved $13^{\text {th }}$ October 2013 from http://trid.trb.org/view.aspx?id=1099844

Mellanby, A. R., Rees, J. B. \& Tripp, J. H. (2000) Peer-led and adult-led school health education: a critical review of available comparative research. Health Education Research, 15, 533-545.

Moller, M., \& Haustein, S. (2014). Peer influence on speeding behaviour among male drivers aged 18 and 28. Accident Analysis \& Prevention, 64, 92 - 99.

Neter, J., Wasserman, W. \& Kutner, M. H. (1989). Applied Linear Regression Models. Homewood, IL: Irwin.

Nunnally, J. (1978). Psychometric methods. New York: McGraw Hill.

ONS. Mortality statistics: deaths registered in 2014.

Ouimet, M.C., Simons-Morton, B.G., Zador, P.L., Lerner, N.D., Freedman, M., \& Duncan, G.D. (2010). Using the U.S. National Household Travel Survey to estimate the impact of 
passenger characteristics on young drivers' relative risk of fatal crash involvement. Accident Analysis \& Prevention, 42, 689-694.

Ouimet, M.C., Pradhan, A.K., Simons-Morton, B.G., Divekar, G., Mehranian, H., Fisher, D.L. (2013). The effect of male teenage passengers on male teenage drivers: Findings from a driving simulator study. Accident Analysis \& Prevention, 58, 132 - 139.

Preusser, D. F., Ferguson, S. A., \& Williams, A. F. (1998). The effect of teenage passengers on fatal crash risk of teenage drivers. Accident Analysis and Prevention, 30, 217- 222

Rhodes, N., Pivik, K., \& Sutton, M. (2015). Risky driving among young male drivers: The effects of mood and passengers. Transportation Research Part F: Psychology and Behaviour, 28, 6576.

Rice, T.M., Peek-Asa, C., \& Kraus, J.F. (2003). Nighttime driving, passenger transport, and injury crash rates of young drivers. Injury Prevention, 9, 245 - 250.

Scott-Parker, B., Watson, B., King, M. J. (2009). Understanding the influence of parents and peers upon the risky behaviour of young drivers. Transportation Research Part F, 12, 470-482

Scott-Parker, B., Watson, B., King, M.J., \& Hyde. M.K. (2014). Young novice drivers and the risky behaviour of parents and friends during the Provisional (intermediate) license phase: A brief report. Accident Analysis \& Prevention, 69, 51 - 55.

Scott-Parker, B., Watson, B., King, M.J., \& Hyde, M.K. (2012). The influence of sensitivity to reward and punishment, propensity for sensation seeking, depression, and anxiety on the risky behaviour of novice drivers: a path model. British Journal of Psychology, 103, 248267.

Siegel, D. J. (2014). Brainstorm: the power and purpose of the teenage brain. New York, NY: The Penguin Group.

Sela-Shayovitz, R. (2008). Young drivers' perceptions of peer pressure, driving under the influence of alcohol and drugs, and involvement in road accidents. Criminal Justice Studies, 21, 3-14.

Shope, J.T., \& Bingham, C.R. (2008) Teen driving: Motor vehicle crashes and factors that contribute. American Journal of Preventative Medicine, 35, 261-271.

Simons-Morton, B., Lerner, N., \& Singer, J. (2005). The observed effects of teenage passengers on the risky driving behaviour of teenage drivers. Accident Analysis and Prevention, 37, 973 982. 
Simons-Morton, B. G., Ouimet, M. C., Zhiwei, Z., Lee, S. L., Klauer, S. E., Wang, J., Chen, R., Albert, P. E., \& Dingus, T. E. (2011). The Effect Of Passengers And Risk-Taking Friends On Risky Driving And Crashes/Near Crashes Among Novice Teenagers. Journal of Adolescent Health, 49, 587-593.

Steinberg, L. (2004). Risk taking in adolescence: What changes, and why? Annals of the New York Academy of Sciences, 1021, 51-58.

Steinberg, L., \& Monahan, K.C. (2007). Age differences in resistance to peer influence. Developmental Psychology, 43, 1531-1543.

Story, M., Lytle, L.A., Birnbaum, A.S., \& Perry, C.L. (2002). Peer-led, school-based nutrition education for young adolescents: feasibility and process evaluation of the TEENS study. The Journal of School Health, 72, 121 - 127.

Tajfel, H. (1982). Social psychology of intergroup relations. In M. R. Rosensweig \& L. W. Porter (Eds.), Annual review of psychology (Vol. 33, pp. 1-39). Palo Alto, CA: Annual Reviews.

Taubman-Ben-Ari, O., Kaplan, S., Lotan \& T., \& Prato, C.G. (2015). Parents’ and peers' contribution to risky driving of male teen drivers. Accident Analysis \& Prevention, 78, 81 86.

Tisdale, S. M. (2013). U in the Driver Seat: A peer-to-peer pilot program for decreasing car crashes by college students. Tamu, Texas: Texas A \& M Transportation Institute.

White, S., Park, Y.S, Israel, T., \& Corderio, E.D. (2009). Longitudinal evaluation of peer health education on a college campus: impact on health behaviours. Journal of American College Health, 57, $497-506$.

Williams, A. F. (2003). Teenage drivers: patterns of risk. Journal of Safety Research, 34, 5 - 15. Williams, A. F., Ferguson, S. A., \& McCartt, A. T. (2007). Passenger effects on teenage driving and opportunities for reducing the risks of such travel. Journal of Safety Research, 38, 381-390.

Williams, A .F. \& Shabanova, V.I. (2002). Situational Factors in Seat Belt Use by Teenage Drivers and Passengers. Traffic Injury Prevention, 3, 201 - 204.

Williams, A.F., \& Tefft, B.C. (2014). Characteristics of teens-with-teens fatal crashes in the United States, 2005-2010. Journal of Safety Research, 48, 37-42. 